Article

\title{
Evaluation of Sustainability of Maize Cultivation in Poland. A Prospect Theory-PROMETHEE Approach
}

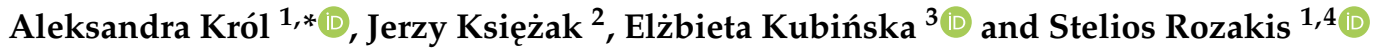 \\ 1 Department of Bioeconomy and Systems Analysis, Institute of Soil Science and Plant Cultivation-State \\ Research Institute, 8 Czartoryskich St, 24-100 Puławy, Poland; srozakis@iung.pulawy.pl \\ 2 Department of Forage Crop Production, Institute of Soil Science and Plant Cultivation-State Research \\ Institute, 8 Czartoryskich St, 24-100 Puławy, Poland; jksiezak@iung.pulawy.pl \\ 3 School of Law and Finance, Cracow University of Economics, 27 Rakowicka St, 31-510 Cracow, Poland; \\ elzbieta.kubinska@uek.krakow.pl \\ 4 School of Environmental Engineering, Technical University of Crete, Kounoupidiana, 73100 Chania, Greece \\ * Correspondence: akrol@iung.pulawy.pl; Tel.: +48-814-786-897
}

Received: 3 October 2018; Accepted: 15 November 2018; Published: 18 November 2018

\begin{abstract}
This study aims at exploiting research outcomes concerning tillage practices in order to make solutions available to farmers to mitigate negative environmental impact to soils. Two alternative practices have been analysed against conventional full tillage based on data provided by a long-term experiment conducted at the Institute of Soil Science and Plant Cultivation (IUNG) farm in Grabów, Central Poland. Reduced Tillage and Direct Sowing are evaluated against Full Tillage on the basis of socio-economic and environmental criteria. Multi-criteria decision analysis undertaken using the PROMETHEE method provided evidence that the 'optimal' maize cultivation system depends on the decision maker's viewpoint and preferences. In fact, criteria selected and related weights elicited from representative farmers, as well as from an expert agronomist, reveal different viewpoints. Direct sowing was the most preferable for the large farm and expert perspective, whereas in case of small farm reduced tillage ranked first. Prospect theory developed by behavioural economists was incorporated to take into account decision biases. As a matter of fact, based on Prospect Theory-PROMETHEE from the small farm and the expert perspective, the conventional system was now ranked first, while for the large farm, the most preferable practice was still direct sowing.
\end{abstract}

Keywords: maize; tillage systems; multiple-criteria decision analysis; PROMETHEE; prospect theory

\section{Introduction}

Intensification of cropping systems as a result of the green revolution has increased manifold productivity at the expense of the physical and social environment. Especially in cases of monoculture, exacerbated profits are compensated by harmful environmental impacts and excessive dependence on markets. Numerous research projects have been funded in various countries to seek solutions and to attain efficient alternatives to this issue. Diverse cultivation techniques and crop rotations have been experimented with and suggested for this purpose. Nevertheless, conventional systems persist as mainstream practices, even if the alternative traditional or innovative techniques appear to outperform them in a multiple-criterion decision space.

Maize seems to be a typical example that illustrates the above reasoning. The area cultivated in Poland has more than doubled in the last two decades, reaching almost 1,200,000 hectares, with a 50-50 split between grain and silage use [1]. In recent years, there has been increased interest in its cultivation for silage, especially in the North-Eastern regions of Poland, as it provides green matter 
yields twice as high as other fodder cereals. However, further expansion of maize cultivation in monoculture will increase greenhouse gas (GHG) emissions, so it is imperative to provide tools to evaluate alternatives. Based on information from an experimental field, we assessed the impact of direct sowing (DS), reduced tillage (RT) and conventional tillage (CT) systems in maize monoculture cultivation on maize yield and soil properties in order to provide documented alternatives to Polish farmers. Significant differences can be observed between DS and CT systems: in CT, maize residues are shredded and turned under, while in DS they are left on the soil surface.

Analysis of sustainability of agricultural practices should be based on simultaneous consideration of economic, environmental and social dimensions. This requires knowledge from different disciplines along with decision support methods that can handle the complexity of the issue taking into account the subjective importance of relevant objectives and goals. Multicriteria methods provide such a framework, with a multitude of applications related to sustainability in agriculture. Among an increasing number of multicriteria algorithms and tools, Sadok et al. published a critical review for the selection of methods suitable for the sustainability assessment of cropping systems [2]. They took into account not only technical criteria from the operations research field but also the specificities related to the application domain; basic features allowing for incommensurability, non-compensation and incomparability are adequately fulfilled by outranking methods. In the context of decision on crop selection by farmers, outranking methods have been applied by various authors in different contexts [3-7]. However, the number and the scope of applications is rather limited; especially where policy-making support is concerned, such models are mainly used to select and rank alternatives and not to evaluate policy measures and/or quantitatively determine support to farmers to implement the chosen alternative.

In this study, the PROMETHEE method is implemented, as it satisfies the prerequisites of Sadok et al., providing two variants: the first allows for incomparability, whereas the second results in a complete preorder of alternatives [2]. Weighting of different preference sets concerning typical stakeholders are determined by means of the Analytical Hierarchy Process (AHP) as suggested in the literature. Moreover, we used this multicriteria algorithm to estimate marginal additional value in one criterion required to reverse ranking. As a matter of fact, the additional farm gross profit (GP) to alternative tillage practices for the farmers is calculated so that they replace CT. This corresponds to the approximate level of environmental support on top of the direct area payment under the current policy scheme.

To make sense when estimating the level of necessary subsidy to incite the farmer to select the benign practices to the environment, a model that approximates real choices needs to be used. For this purpose, we adopted a novel version of PROMETHEE that takes into account findings of the behavioural science and economics, incorporating in the original algorithm elements of the Prospect Theory.

Farmers consider any novelty proposed by farm advisors to be against current knowledge and conventional practices. Being risk averse and operating in an uncertain environment, they feel losses more than equivalent gains. Increasing weather variability and the specificity of maize cultivation oblige particular attention to risk approximated by standard deviation introduced as additional criterion both in the case of profit and of environmental impacts. On the other hand, advances in behavioural economics offer theoretical bases to simulate realistic behaviour so as to reflect the context and peculiarities of the decision makers. As a matter of fact, prospect theory uses cognitive psychology elements to describe the way people select alternatives under risky conditions. Its promoters provide evidence that people think of lotteries, over-evaluating losses versus gains, thus it provides a descriptive model able to reproduce real-life choices instead of searching optimal decisions, identifying as a positive rather than a normative approach. The theory was developed by Daniel Kahneman and Amos Tversky as a psychologically more accurate description of decision making, compared to the expected utility theory [8]. 
In particular, the elements of reference dependency and loss aversion can be functionally integrated in outranking multi-criteria (MC) algorithms, precisely in PROMETHEE implementing Prospect Theory ideas and guidelines [9]. Thus, a discrete reference alternative incorporating elements of prospect theory is included in the analysis. Loss aversion is then expressed with respect to this reference.

In this study, we apply the above methodology to evaluate and to rank climate change adaptation practices regarding tillage for maize cultivation in Poland. The tillage issue related to maize cultivation sustainability followed by the description of experimental design and outcomes of the field experiment are detailed in the next section. Next, AHP and PROMETHEE algorithms, as well as principles of prospect theory and their integration to PROMETHEE are detailed. Implementation of multicriteria analysis and its results and discussion are presented in Section 3. The conclusive comments completing the paper are presented in Section 4.

\section{Materials and Methods}

\subsection{Sustainability in Maize Cultivation}

Research on management of maize cultivation that would reduce energy use and would improve the yield has been carried out for many years. Maize is a crop that can be cultivated in continuous cropping schemes for several years [10]. It can also be cultivated in no-tillage systems with appropriate mulching. Introduction of tillage reduction in maize cultivation systems is mostly done due to economic and environmental considerations [11].

Sustainable Crop Production Intensification (SCPI) assumes efficient and cost-effective agricultural production with adequate productivity growth, while ensuring conservation of resources, reduction of harmful environmental impact, and enhancement of natural capital [12]. Sustainable agriculture aims for the maintenance of environmental health, economic profitability, and social and economic equity. Nowadays, due to growing human needs, there is a need to solve problems related to climate change, increase of biodiversity loss, degradation, and pollution of land and water resources [13]. In accordance with SCPI, farming systems should based on conservation agriculture practices, good seeds of high-yielding varieties, and integral fertilization and pest management based on healthy soils, water and resource efficiency, and integration between crops, trees, pastures and livestock [12]. Nowadays, conservation agriculture is increasingly being promoted by several international research and development organizations [14]. According to the FAO, conservation agriculture (CA) is considered a sustainable production system that can sequester carbon and reduce GHG emissions. CA is also related to lower fuel and repair costs due to the lower number of machines and passes over fields required [15].

The adaptation practices for reducing the negative effect of climate change on agriculture are mainly related to changes in soil tillage systems, which lead to soil moisture improvement and reduction of production costs. Conservational tillage may be introduced for this purpose [16]. In recent years, increasing interest has been paid to the development of conservation tillage systems as alternative management systems. Traditional CT involves inversion of the soil with a disc plough or mouldboard. Conservational tillage refers to low tillage, by not inverting soil, and leaves plant residues $(30 \%)$ on the soil surface in order to reduce soil erosion and improve soil water storage.RT refers to soil tillage using rotary harrows or grubbers with string roller instead of a plough. The crop is sown to harvest residues after shallower tillage. DS relates to crop sown directly into the soil after Roundup application and no application of tillage since the harvest of the previous crop. Weed control has to be achieved by use of non-selective herbicides [11]. DS leads to the highest saving in costs and energy. In comparison to traditional tillage, DS reduces energy use by $70 \%$ [11]. Despite the fact that traditional tillage has certain limitations, such as faster rate of organic matter mineralization, reinforced water erosion and soil density improvement, it is still the dominant way for agriculture cultivation, because it is related to higher yields [17-19]. However, nowadays, it is increasingly being seen that reduction in soil tillage 
practices is not only related to cost, labour, erosion and surface runoff reduction, but also to soil water storage improvement $[17,20-22]$.

Innovative practices to replace the dominant tillage system in Poland (the most energy-intensive, expensive and soil-degrading agrotechnical operation) with different soil cultivation techniques (conservation farming) need to be thoroughly monitored and evaluated before implementation in commercial farms. Reduction in tillage systems may drastically reduce yields and economic profitability if crop management is not adequate, e.g., deficient application of herbicides [19]. Alternatives examined in this exercise followed experimental design that ensured agronomic management rules based on state-of-the-art scientific knowledge.

The hypothesis of the field experiment was to investigate the impact of reduced or no tillage on maize yield and related environmental indicators. Due to the fact that the price of agricultural inputs has been increasing more and more, IUNG agronomists have been motivated to study efficient tillage systems by means of long-term experiments. Conservational tillage may reduce costs of production, and at the same time, it may improve environmental dimensions by increasing soil moisture, drainage, and water holding capacity, and decreasing soil erosion and runoff. Regrettably, short-term economic benefits may be counterbalanced by yield reduction caused by an increase in the occurrence of weeds, pests and diseases, as well as additional costs associated with these [14]. Thus, conservational tillage may have positive and negative impacts on crop production, and the choice of the "optimal" cultivation system may be problematic and dependent on point of view. Due to growing production constraints, farmers must integrate information from various fields: economics, environment, society, health, and even geopolitics. This influences in the need for development of the decision support systems (DSSs) with the aim of providing farmers to facilitate decision-making [23], for this purpose MCDM methods may be used.

\subsection{Case Study}

A long-term field experiment was established in 2004 at the Experimental Station of the Institute of Soil Science and Plant Cultivation-State Research Institute in Grabów, Masovian Voivodeship, Central Poland $\left(51^{\circ} 21^{\prime} \mathrm{N}, 21^{\circ} 40^{\prime} \mathrm{E}\right)$ to assess the impact of tillage systems in maize monoculture cultivation on maize yield and soil properties. The study area has continental climate with a long-term average annual rainfall of $630 \mathrm{~mm}$. The soil type is lessive soil formed from a light loam. The experiment was designed to compare influence of the following treatments on crop and soil:

1. Maize monoculture-zero tillage (direct sowing, DS)

2. Maize monoculture-reduced tillage, RT

3. Maize monoculture-full ploughing tillage, conventional tillage, $\mathrm{CT}$

On many large-size farms, maize grown under continuous schemes with several years' duration was observed more frequently than short maize monoculture schemes. In monocultures, instead of removing the straw from the field (after cob's harvesting) for fodder, maize residues are rather shredded and turned under (CT) or left on the soil surface (DS, RT). In this practice, almost half of the produced biomass returns to the soil, improving soil organic substance and nutrient content [10].

The analysed alternatives of maize cultivation practices differ in materials and operations used (Table 1). In all cases, cv LG.30.260 was seeded at an amount of $30 \mathrm{~kg} \mathrm{ha}^{-1}$. Especially for DS, a precision maize planter was used. In all maize cultivation practices, nitrogen, phosphorus and potassium was applied at a rate of $140 \mathrm{~kg} \mathrm{~N} \mathrm{ha}^{-1}(70+70), 80 \mathrm{~kg} \mathrm{P}_{2} \mathrm{O}_{5} \mathrm{ha}^{-1}$ and $125 \mathrm{~kg} \mathrm{~K}_{2} \mathrm{O} \mathrm{ha}^{-1}$, respectively [10]. In the case of plant protection of maize, in all cultivation practices, herbicide (Maister $310 \mathrm{WG})$ at an amount of $1.5 \mathrm{~L} \mathrm{ha}^{-1}$ was dosed with Actirob $842 \mathrm{EC}\left(2 \mathrm{~L} \mathrm{ha}^{-1}\right)$. In DS and RT, two kinds of herbicides were additionally applied (Roundup 360 SL, Reglone 200 SL) at amounts of $3 \mathrm{~L} \mathrm{ha}^{-1}$ each. The analysed cultivation practices, besides their materials, differ in the kind of and number of operations. In DS, only disk cultivation was performed, in RT, and CT there were two cultivation operations. In all practices, fertilisers were applied three times (one PK and two N 
fertilisation applications). Plant protection products were implemented once in CT, while in DS and RT systems they were applied three times. Long-term experimental data allow for consideration of variability in yields. Thus, DS yields give averages of 6.41 and $13.34 \mathrm{tha}^{-1}$ (with standard deviations of 2.26 and $3.34 \mathrm{t} \mathrm{ha}^{-1}$ ) for grain (at 15\% moisture level) and dry matter, respectively. Full tillage average yield amounts at 7.3 and $14.98 \mathrm{t} \mathrm{ha}^{-1}$ for grain (at $15 \%$ moisture level) and dry matter, respectively (with standard deviations are higher amounting at 3.89 and $4.84 \mathrm{t} \mathrm{ha}^{-1}$ for grain and dry matter, respectively). RT average yield amounts to 7.95 and $14.78 \mathrm{tha}^{-1}$ for grain (at 15\% moisture level) and dry matter, respectively (with standard deviations of 4.45 and $5.89 \mathrm{t} \mathrm{ha}^{-1}$ for grain and dry matter, respectively). Calculations on DS and CT practices are based on the 2004-2016 time series; the RT experiment was started in 2013 , so the data set refers to four harvests only.

Table 1. Materials and operations applied in different maize cultivation practices.

\begin{tabular}{|c|c|c|c|}
\hline & DS & RT & $\mathrm{CT}$ \\
\hline Seeds $\left(\mathrm{kg} \mathrm{ha}^{-1}\right)$ & 30 & 30 & 30 \\
\hline $\mathrm{N}$ fertilisers $\left(\mathrm{kg} \mathrm{ha}^{-1}\right)$ & 140 & 140 & 140 \\
\hline $\mathrm{P}_{2} \mathrm{O}_{5}$ fertilisers $\left(\mathrm{kg} \mathrm{ha}^{-1}\right)$ & 80 & 80 & 80 \\
\hline $\mathrm{K}_{2} \mathrm{O}_{5}$ fertilisers $\left(\mathrm{kg} \mathrm{ha}^{-1}\right)$ & 125 & 125 & 125 \\
\hline Fungicides $\left(\mathrm{L} \mathrm{ha}^{-1}\right)$ & 0 & 0 & 0 \\
\hline Herbicides ( $\left.\mathrm{L} \mathrm{ha}^{-1}\right)$ & 9.5 & 9.5 & 3.5 \\
\hline Grown regulator $\left(\mathrm{L} \mathrm{ha}^{-1}\right)$ & 0 & 0 & 0 \\
\hline Fuel $\left(\mathrm{L} \mathrm{ha}^{-1}\right)$ & 60 & 71 & 80 \\
\hline Cultivation & 1 & 3 & 3 \\
\hline Manure fertilisation & 0 & 0 & 0 \\
\hline PK fertilisation & 1 & 1 & 1 \\
\hline $\mathrm{N}$ fertilisation & 2 & 2 & 2 \\
\hline Plant protection & 3 & 3 & 1 \\
\hline
\end{tabular}

Source: [24,25], www.lcagri.pl: Research to support for low-carbon agriculture to adapt to observed climate change in the horizon 2050 .

\subsection{Setting Criteria for Decision Making}

The overall objective is to provide evidence regarding tillage practices for the sustainable cultivation of maize in Poland. Sustainability refers to the long-term survival of a system; thus, environmental goals (i.e., protection of soil and water resources and climate change mitigation) should be pursued in parallel to social and economic objectives by farm businesses and agricultural households (i.e., increase farm income, reduce energy consumption, working time and labour costs). A picture of conflicting objectives is thus drawn with respect to appropriate methods to determine the most efficient compromise alternatives ensuring sustainability.

In this study, we adopted a comprehensive set of 6 criteria, two for each of three dimensions, namely environmental, financial and socio-economic ones. Criteria were selected after consultation with farmers and experts related to environmental, economic and social issues, and drilling information from scientific field experiments. There is evidence that various stakeholders attach different importance to criteria, or may select different criteria altogether, with experts and farmers placing more weight on financial and economic objectives, while policy makers and the public emphasize social and environmental priorities [26]. The multicriteria analysis process enhances the dialogue between agricultural policy makers, environmentalist and farmers, facilitating the search of a compromise solution.

\subsubsection{Environmental Criteria}

Soil organic carbon (SOC), measured in percentage. According to EU soil strategy of 2002, maintain of soil organic matter is one of the major tenets in prevention of soil erosion [10]. Soil organic matter has significant influence on water retention capacity. Changes in soil organic matter caused by reduction of soil tillage practices have been already presented [27]. Higher indicator values designate more sustainable farms in terms of maintaining soil fertility. 
Soil moisture (SM), measured in \%, $v / v$. Parcels with higher SM are more sustainable than others. The changes in soil tillage systems may lead to soil moisture improvement. Conservational tillage may be introduced for this purpose [16]. In previous studies, soil moisture under no-tillage (NT) and RT systems was higher than in traditional tillage systems [21,28-30].

\subsubsection{Financial Criteria}

Mean gross profit (GP), in euro. Gross profit is used instead of net profit; thus, we do not consider depreciation of durable goods because we compare different versions of the same crop, and the machinery used is readily available in arable farms, and pieces of machinery not available are rented.

Standard deviation gross profit (SD), measured in euro is the dispersion measure used to take into account time series of 10 annual average yields provided by experimental fields. The lower the standard deviation, the higher the farm's income stability and, consequently, economic sustainability.

\subsubsection{Socio-Economic Criteria}

Labour, in hours, of the "more is better" kind from the social point of view (higher numbers of jobs are desirable) and the "more is worse" kind from the economical perspective. Small versus large farms offer different viewpoints regarding labour.

Fuel, in litres. Energy contained in inputs mainly concerns tillage, one of the major energy demanding operations in arable cultivation. The higher the values of energy consumed the less profitable, the higher GHG emissions to the atmosphere and the more dependent on oil imports is the agricultural activity. This is a multifaceted indicator; thus, we classify it as a socio-economic one.

\subsection{Multicriteria Decision Analysis Methodology}

An integrated approach for the decision-making problem is followed that combines the Analytical Hierarchy Process (AHP) and the Preference Ranking Organization Method for Enrichment Evaluations (PROMETHEE) in order to achieve operational synergies [31]. AHP facilitates criteria ranking and weighting, then preferences are conveyed to PROMETHEE to select the most efficient alternative for the decision-maker [32]. Thus, sustainability evaluation of different maize tillage practices is performed by means of multicriteria techniques. The sequence described in Figure 1 is detailed in four steps:

1. Selection of objectives or attributes and related indicators

2. Determination of relative importance (weights) of indicators selected

3. Ranking of tillage practices from different viewpoints

4. Exploration of financial incentives to improve sustainability

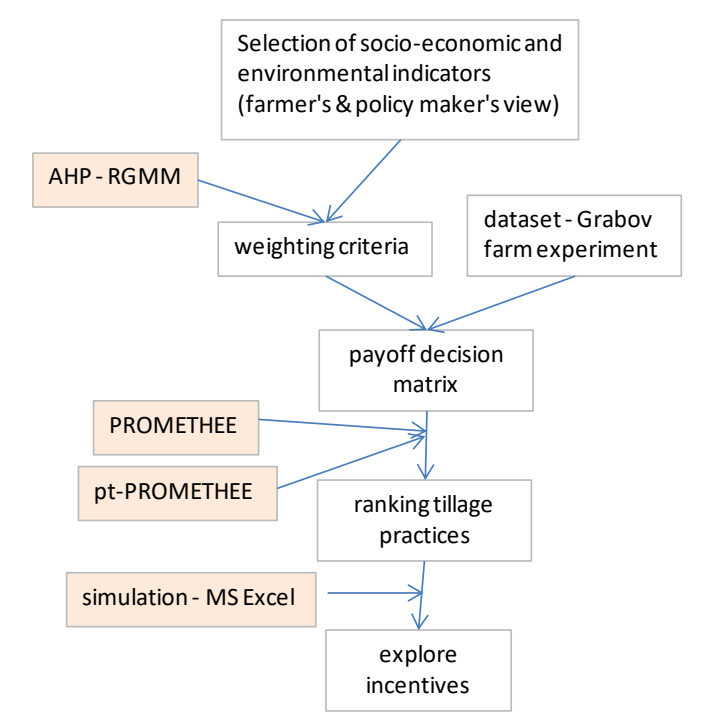

Figure 1. Outline of the methodological approach. 


\subsubsection{The Analytic Hierarchy Process (AHP) Method}

We opted to explore the set of examined alternatives in light of two distinct viewpoints corresponding to the farmers and the policy makers. The weights of the abovementioned criteria were determined based on a questionnaire (AHP, [33]). Weights correspond to trade-offs across indicators measuring decision makers' willingness to forego a given variable in exchange for another.

The decision makers' answers to the series of pairwise questions "How important is criterion A relative to criterion B?" is the main input to the AHP method. Responses are attributed to a nine-point intensity scale, from 1 (equally important), through 3 (moderately more important), 5 (strongly more important) and 7 (very strongly more important) to 9 (overwhelmingly more important). The results are represented in a comparison matrix where $a_{i i}=1$ and $a_{i j}=1 / a_{j i}$. The matrix of the pairwise comparisons would be $A=\left[a_{i j}\right]$, and according to Saaty, the vector of weights is the solution of the eigenvalue problem $A w=\lambda_{\max } w$ with $\sum_{i} w_{i}=1$ and $\lambda_{\max }$ greater or equal to $n$ (the rank of the matrix

A) [34]. After normalization of the eigenvector corresponding to the largest eigenvalue, the weights are determined. A close approximation of the eigenvector is provided by the logarithmic least squares method, implying calculation of the normalised row geometric means. The local priority of each element is obtained by the normalization (distributive mode) of the row geometric mean associated with this element in the positive reciprocal matrix A [35]. The weights are calculated by the function:

$$
w_{i}=\left(\prod_{j=1}^{n} w_{i j}\right)^{1 / n} / \sum_{i=1}^{n}\left(\prod_{j=1}^{n} w_{i j}\right)^{1 / n}
$$

By default, judgments of pairwise comparison matrix elements do not present perfect consistency; nevertheless, natural inconsistency should vary within reasonable limits. A consistency ratio (CR) is calculated for this purpose. Given that perfect consistency would result in $\lambda_{\max }$ equal to $n$, Saaty suggested considering their difference divided by $\mathrm{n}$ minus one; in other words, the average of remaining eigenvalues, thus $\mathrm{CI}=\frac{\lambda_{\max }-1}{n-1}$ [33]. The CR is calculated by dividing the $\mathrm{CI}$ by the mean random CI generated by large samples of purely random judgments. According to Saaty, the suggested rule of thumb is that CR should not exceed 0.1 [33], with some authors tolerating values of up to 0.2 [36]. The use of the right eigenvector method is associated with the possible occurrence of the rank reversal paradox. The rank reversal problem in AHP / ANP lies in the fact that solving the decision problem using the right eigenvector method should give a reverse to the ranking obtained using the left eigenvector method. The geometric mean is free from this disadvantage [37]. Additionally, according to Aguaron and Moreno-Jimenez, the consistency ratio should be calculated in such way that it is adapted to the geometric mean. The method of calculating the geometric consistency ratio (GCI) and corresponding approximated thresholds, as explained in [38] (the corresponding thresholds for GCI are 0.31 for $n=3,0.35$ for $n=4$ and 0.37 for $n>4$ ).

\subsubsection{Overview and Taxonomy of PROMETHEE Methods}

Among the several methods of multicriteria decision-making aids, outranking methods have presented a rapid development during the last decade because of their adaptability to the poor structure of most real decision situations. The PROMETHEE method, which is among the most known and widely applied outranking methods, consists of the construction of an outranking relation through the pairwise comparison of the examined alternatives in each separate criterion [39]. By introducing several types of criteria, PROMETHEE allows for an enrichment of preference structures that is suitable for handling uncertainty or imprecision characterising ill-structured problems. It namely suggests six types of generalised criteria accepting thresholds for delimiting the indifference and preference area, as well as intermediate preference states. 
Let $N$ be the set of alternatives and $M$ be the set of criteria. A preference function is defined through the pairwise comparison of the alternatives in each criterion $j$ as:

$$
P_{j}(N \times N) \rightarrow\langle 0,1\rangle j \in M
$$

For two alternatives $a$ and $b$ in $N$ we have [40]:

$P_{j}(a, b)=0 \Rightarrow$ Indifference between $a$ and $b$ or an outranking of $b$ over $a$ in the $j$-th criterion

$P_{j}(a, b) \sim 0 \Rightarrow$ Weak preference of $a$ over $b$ in the $j$-th criterion

$P_{j}(a, b) \sim 1 \Rightarrow$ Strong preference of $a$ over $b$ in the $j$-th criterion

$P_{j}(a, b)=1 \Rightarrow$ Strict preference of $a$ over $b$ in the $j$-th criterion

The preference function is a non-decreasing function of the difference $d_{j}$ between the performances of the two alternatives in $j$-th criterion:

$$
\begin{gathered}
d_{j}=\left\{\begin{array}{cc}
p_{a j}-p_{b j} & \text { if } p_{a j} \geq p_{b j} \\
0 & \text { otherwise }
\end{array}\right. \\
P_{j}(a, b)=f\left(d_{j}\right)
\end{gathered}
$$

where $p_{a j}$ and $p_{b j}$ are the performance of alternatives $a$ and $b$ in $j$-th criterion. It must be noted that the above relation holds if $j$ is a maximization criterion; if it is a minimization criterion, we must reverse the signs of $p_{a j}$ and $p_{b j}$ and then apply Equation (3).

The functional form of $f$ is decided by the decision maker. Six types of functional forms are available, and they are called generalised criteria or pseudo-criteria. Three kinds of parameters are defined: the indifference parameter $(q)$, the strict preference parameter $(p)$ and the Gaussian parameter $(\sigma)$. The type of each criterion, as well as the values of the parameters $(q, p$ and $\sigma)$, is decided by the decision maker. The multicriteria preference index of alternative $a$ over alternative $b$ is defined by weighting the calculated preference functions $P_{j}(a, b)$ according to the weights of importance $\left(w_{j}\right)$ the decision maker is attaching to each criterion as follows:

$$
\prod(a, b)=\frac{\sum_{j=1}^{m} w_{j} \times P_{j}(a, b)}{\sum_{j=1}^{m} w_{j}}
$$

where $m$ is the number of criteria. The multicriteria preference index $\Pi(a, b)$ represents the intensity of preference of alternative $a$ over alternative $b$ as perceived by this decision maker. By repeating this procedure for every pair of alternatives we obtain a $n \times n$ matrix $(n=$ number of alternatives, $n=\operatorname{card}(N))$ with all the preference indices $\Pi(j, k)$ values.

It must be noted that the above square matrix is not symmetrical $(\Pi(a, b) \neq \Pi(b, a)$ in general). The row sum of this matrix gives the outranking character of the corresponding alternative while the column sum gives the outranked character of the corresponding alternative. That is, the greater the row sum (or leaving flow) of alternative $a$, the better it is in comparison with the other alternatives. On the contrary, the greater the column sum (or entering flow) of alternative $a$, the worse it is in comparison with the other alternatives.

The leaving and entering flows for alternative $a$ are defined as follows:

$$
\begin{aligned}
& \text { leaving flow : } \varphi^{+}=\sum_{i=1}^{n} \Pi(a, i) \\
& \text { entering flow }: \varphi^{-}=\sum_{i=1}^{n} \Pi(i, a)
\end{aligned}
$$

By combining the rankings provided on the basis of the leaving and entering flows we obtain a partial preordering of the alternatives (PROMETHEE I), which accepts incomparabilities among some 
actions. According to the partial preorder, an alternative $a$ outranks alternative $b$ if $\varphi^{+}(a) \geq \varphi^{+}(b)$ and $\varphi^{-}(a) \leq \varphi^{-}(b)$ with at least one strict inequality; or if $\varphi^{+}(a)=\varphi^{+}(b)$ and $\varphi^{-}(a)=\varphi^{-}(b)$, then $a$ is indifferent to $b$ and $a$ is incomparable to $b$ in any other case. Incomparability usually arises when an alternative $a$ is good on a set of criteria on which $b$ is weak and, reciprocally, $b$ is good on another set of criteria on which $a$ is weak. It is clear that such a situation very often happens in real-world decision problems.

To obtain the complete preorder of the examined alternatives (PROMETHEE II), the net flows are calculated as the difference between leaving and entering flows:

$$
\text { net flow : } \varphi(a)=\varphi^{+}(a)-\varphi^{-}(a)
$$

In this case, alternative $a$ outranks $b$ if $\varphi(a)>\varphi(b)$ and $a$ is indifferent to $b$ if $\varphi(a)=\varphi(b)$. Consequently, PROMETHEE II allows for a complete ranking of the examined alternatives in decreasing order of preference.

Along with the applications of the PROMETHEE method in various fields, there are also new methodological modifications of the method. For example, in the case of the environmental assessment of production techniques, PROMETHEE has been adopted towards the evaluation of fuzzy data on preferences, scores and weights [41]. The next example is the evaluation of alternative energy exploitation scenarios for the development of local resources, in this case the PROMETHEE method is extended to deal with fuzzy input data, too [42]. The next approach that exploits the fuzziness of objects and the hesitant thinking of decision makers is presented in [43], where the PROMETHEE method integrates some elements of thermodynamics and cumulative prospect theory. By referring to cumulative prospect theory, decision maker's psychological behaviour is reflected, while hesitant fuzzy linguistic energy and exergy reflect the quantity and quality of available decision-making information. For the sake of simplicity and clarity of the computational procedure in fuzzy PROMETHEE, a new fuzzy MCDM method called the New Easy Approach to Fuzzy PROMETHEE (NEAT F-PROMETHEE) is introduced. It is characterized by low complexity in dealing with fuzzy numbers and by consistency with the methodological assumptions of the classical PROMETHEE method [44]. Another generalization of PROMETHEE method deals with the case of the hierarchical structure of criteria, and is proposed in [45]. By means of Robust Ordinal Regression, in addition to the final ranking of alternatives, it is possible to determine preferences on the different levels of the criteria structure; the results are more compatible with the preference information elicited by the decision maker. The next modification is PROSA [46], which is the PROMETHEE method for Sustainability Assessment. PROSA aims to fulfil the postulate of strong sustainability by limiting the negative effect of linear compensation of criteria. A dynamic decision support method based on the PROMETHEE in an online environment framework was proposed in [47].

\subsubsection{Integration of Prospect Theory to PROMETHEE}

There have already been attempts to integrate prospect theory into the PROMETHEE method. The reference points and loss aversion for alternative attributes are incorporated into the preference functions used in pairwise comparisons in PROMETHEE. Fan et al. introduced a new preference function with reference to the analytical formula for the value function in prospect theory, and the $\mathrm{V}$-shape preference function with indifference threshold (Type 5 in PROMETHEE) [48]. Lerche and Geldermann modified all 6 types of preference function in PROMETHEE by adjusting the slope for negative difference in the attribute values [9].

As both the preference functions and the value function of prospect theory are defined with respect to differences, preference functions seem to be advantageous in terms of incorporating loss aversion reasonably well. In prospect theory, loss aversion is represented by a steeper slope for losses within the value function. The degree of loss aversion is determined by the coefficient $\lambda=2.25$, which was 
estimated by Tversky and Kahneman in their experimental decision making study [49]. Instead of an S-shape value function, for simplicity, the piecewise-linear value function of prospect theory

$$
v(x)= \begin{cases}x, & x \geq 0 \\ \lambda x, & x<0\end{cases}
$$

is transferred into PROMETHEE, where we consider the preference function of Type III (V shape):

$$
f(x)=\left\{\begin{array}{cc}
0, & x<0 \\
\frac{x}{p}, & 0 \leq x \leq p \\
1, & x>p
\end{array}\right.
$$

The loss aversion coefficient is incorporated by using $\lambda x$ instead of argument $x$ in classical preference function, which leads to new preference functions in the domain of losses:

$$
f_{\text {LOSS }}(x)=\left\{\begin{array}{rc}
0, & x<0 \\
\frac{x}{p / \lambda}, & 0 \leq x \leq p / \lambda \\
1, & x>p / \lambda
\end{array}\right.
$$

Loss aversion causes decision makers to be more sensitive to changes, i.e., if before the preference threshold was equal to $p$, then due to the steeper function in the domain of losses, the preference threshold will be reached earlier, at $p / \lambda$ (this results from equation $\frac{\lambda x}{p}=1$ ). The same procedure can also be used in the case of the other five generalized criteria according to Brans et al. [39], adjusting the thresholds $p, q$ and $\sigma$ by dividing by $\lambda$ and replacing an argument in the preference function by $\lambda x$.

Based on the defined reference alternative, the aspect of loss aversion can be integrated into PROMETHEE. As shown by Fan et al., a loss or gain property of an outcome has an asymmetrical impact on its desirability/undesirability with respect to the reference point, and this effect should be considered when determining preferences in PROMETHEE [48]. Within the common procedure of PROMETHEE, we consider preferences between alternatives by specifying the preference function, which is a value between 0 and 1 , and by defining the direction for the optimization of a given criterion. There is no loss idea in the common procedure (for negative arguments, the preference function given by Formula (3) is equal to zero). We believe that loss aversion should be introduced by using a modified preference function $f_{\text {LOSS }}$ in pairwise comparisons in cases where the first alternative is a reference point. This is related to reluctance to change from the reference state, which can be observed in many decision-maker groups. If the reference point is the status quo, then the reluctance to change is called the status quo effect. However, selection, as proposed in the literature in reference points, has advantages and disadvantages. The status quo is relatively easy to determine and is comprehensible for the decision maker, although it eventually neglects some of the expectations or requirements with respect to the overall goal. In cases where expectations are considered a reference point, then any alternative compared with the expectation state will be considered a loss, analogously for minimal requirements.

The elements of reference dependency and loss aversion incorporated into the PROMETHEE method can be used to analyse the status quo effect in multicriteria decisions. We propose the following modification of the PROMETHEE method: (1) status quo is considered to be the reference point, and (2) modifications with regard to loss aversion preference functions are used only in pairwise comparison, where the first alternative is a reference point. Proposed modification is called PT-PROMETHEE, and it shows the status quo effect in multi-criteria decisions. For the purpose of illustrating PT-PROMETHEE, we iteratively selected as reference alternatives all alternatives of the example of hydropower investment from the seminal paper as a benchmark. Performance matrix and parameters for PROMETHEEE and PT-PROMETHEE are shown in Table 2. 
Table 2. Performance matrix and parameters for PROMETHEEE and PT-PROMETHEE.

\begin{tabular}{ccccccc}
\hline Criteria & f1 & f2 & f3 & f4 & f5 & f6 \\
\hline Alternative 1 & 80 & 90 & 6 & 5.4 & 8 & 5 \\
Alternative 2 & 65 & 58 & 2 & 9.7 & 1 & 1 \\
Alternative 3 & 83 & 60 & 4 & 7.2 & 4 & 7 \\
Alternative 4 & 40 & 80 & 10 & 7.5 & 7 & 10 \\
Alternative 5 & 52 & 72 & 6 & 2 & 3 & 8 \\
Alternative 6 & 94 & 96 & 7 & 3.6 & 5 & 6 \\
\hline direction & $\min$ & $\max$ & $\min$ & $\min$ & $\min$ & $\max$ \\
type & 2 & 3 & 5 & 4 & 1 & 6 \\
q (or s) & 10 & & 0.5 & 1 & & 5 \\
p & & 30 & 5 & 6 & & \\
\hline PT: q or s for $\lambda=2.25$ & 4.444 & & 0.222 & 0.444 & & 5 \\
PT: p for $\lambda=2.25$ & & 13.333 & 2.222 & 2.667 & & \\
\hline
\end{tabular}

Criteria: f1—npower. f2-power (MW). f3-construction cost (\$109), f4-maintenance cost (\$106). f5-number of villages to evacuate, f6-security level.

One can observe in Table 3 that when an alternative is considered to be a reference benchmark, its position in the final ranking is improved by at least one step, with only one exception (alternative 2). Thus, alternative 1 ranks 5 instead of 6, alternative 3 ranks 4 instead of 5, alternative 4 ranks second instead of third and alternative 6 ranks second instead of fourth when there is no reference. This finding supports the hypothesis of inertia when compared to the status quo.

Table 3. Results of parametric calculation.

\begin{tabular}{ccccccccc}
\hline \multirow{2}{*}{ Alternatives } & \multirow{\Phi}{*}{$\begin{array}{c}\text { Ranking with No } \\
\text { Reference Alternative }\end{array}$} & \multicolumn{5}{c}{ Ranking with Reference Alternative } \\
\cline { 4 - 8 } & & 6 & $\mathbf{1}$ & $\mathbf{2}$ & $\mathbf{3}$ & $\mathbf{4}$ & $\mathbf{5}$ & $\mathbf{6}$ \\
\hline 1 & -0.728 & 2 & 2 & 6 & 6 & 6 & 6 & 6 \\
2 & 0.086 & 5 & 2 & 2 & 3 & 2 & 3 \\
3 & -0.448 & 3 & 6 & 5 & 4 & 5 & 5 & 5 \\
4 & -0.100 & 1 & 3 & 3 & 3 & 2 & 3 & 4 \\
5 & 1.464 & 4 & 1 & 1 & 1 & 1 & 1 & 1 \\
6 & -0.274 & 4 & 4 & 5 & 4 & 4 & 2 \\
\hline
\end{tabular}

\section{Results and Discussion}

\subsection{Indicators Performance and Implementation of Multicriteria Analysis}

RT and DS may cause negative effects on chemical and physical soil properties, while it can have positive effects on SOC in the surface soil layer [18]. Gałazka et al. analysed SOC in different maize cultivation practices similar to the one in the experimental field [50]. The results obtained show that SOC was lower in RT with regard to CT by $3 \%$. SM values in different maize cultivation practices from the same experimental field were presented by Bojarszczuk et al. [51]. This study shows that SM was significantly higher in DS by $8 \%$ and lower in RT by $12 \%$ than in CT.

The mean GP for different maize cultivation practices was estimated by means of spreadsheet calculations. Previous studies show that DS and RT caused in total dry matter of maize yield decrease [18,28], while Dzienia et al. indicate that conservational tillages can significantly reduce costs related to the production (energy and labour requirements) [17]. Reduction in soil tillage may result in additional need for chemical plant protection application (due to intense weed growth), which is also related to cost increase. Mean GP, estimated for different maize cultivation practices based on 2004-2016 data, was lower in CT than in RT by 5\% and higher than in DS by $20 \%$. The standard deviation (SD) of gross profit was higher in RT by $15 \%$ and lower in DS by $42 \%$, with regard to full tillage, as demonstrated by the fact that mitigation practices may improve yield (agriculture 
production) stability [52]. Fuel consumption is estimated for different maize cultivation practices. The fuel consumption was higher by $24 \%$ in RT and by $32 \%$ in DS than with CT.

The performance matrix (Table 4) shows differences and potential trade-offs between analysed maize cultivation managements. Criteria retained are (1) expected gross margin, (2) standard deviation of gross margin, (3) fuel consumption, (4) labour use in hours, (5) soil moisture, and (6) organic matter in soil.

Table 4. Performance matrix and PROMETHEE parameters.

\begin{tabular}{ccccccc}
\hline Cultivation Method & Mean GP & SD of GP & Fuel & Labour & SM & SOC \\
\hline DS & euro & euro & litres & hours & $\%, v / v$ & $\%$ \\
RT & 497.77 & 307.36 & 65.11 & 3.44 & 16.3 & 0.70 \\
CT & 652.44 & 606.17 & 73.08 & 4.72 & 13.3 & 0.67 \\
Criterion type & 618.48 & 528.92 & 96.10 & 6.34 & 15.1 & 0.69 \\
threshold q (or s) & 6 & 5 & 4 & 2 & 3 & 1 \\
threshold p & 250 & 50 & 5 & 1 & & \\
threshold PT: q (or s) & $*$ & 22.22 & 2.22 & 0.44 & & \\
threshold PT: p & & 66.67 & 8.89 & & 0.66 & \\
\hline Direction (large farm) & Max & Min & Min & Min & Max & Max \\
Weight (large farm) & 41 & 4 & 19 & 18 & 7 & 10 \\
\hline Direction (expert \& small farm) & Max & Min & Min & Max & Max & Max \\
Weight (expert) & 41 & 4 & 19 & 18 & 7 & 10 \\
Weight (small farm) & 66 & 6 & 12 & 16 & 0 & 0 \\
\hline
\end{tabular}

Modification based on lambda incorporated in the Gaussian function.

As we observe in Table 4 all three alternative tillage practices are non-dominated or Pareto efficient: the mean gross profit was higher in RT and full tillage than in DS management. The lowest risk was obtained in the DS system, as well. The lowest fuel consumption was observed in DS and $\mathrm{RT}$, caused by a reduction in the number of soil tillage operations. In terms of different alternatives, demand for labour differed between them, with the lowest labour need being observed in DS and the highest in CT. As presented in Section 2.1, the highest SM was observed in DS and then in RT. The lowest SM was observed in full tillage.

Criteria types and corresponding threshold parameters appear in the lower part of Table 4, as well. Our stylized model assumes three decision makers, the expert/policy maker, a large business farmer and a small farmer. The direction of criteria as they appear in Table 4 (that is, to maximize mean GP (column 1), SM (5) and SOC (6), and to minimize SD of GM, (3) fuel consumption, (4) labour use in hours) identifies the preferences of the business (large) farmer, whereas policy makers perceive labour as a social indicator to be maximised. Regarding small farmers, not surprisingly, since family labour available is usually redundant with regard to crop cultivation requirements, they would prefer to maximise labour. Moreover, small farmers do not include in their selection criteria environmental performance (SM and SOC), so their decisions are based upon four instead of six criteria.

\subsection{Implementation of PT-PROMETHEE}

Based on these assumptions, and using threshold parameters and data from the payoff matrix, we implemented PROMETHEE II, resulting in total $\varphi$ shown in Table 5, denoting the pecking order in the ranking of alternatives. For each viewpoint, the first column denotes the PROMETHEE II outcome and the next one shows the variant PROMETHEE-PT (Prospect Theory). This column takes into account realistic behaviour assumptions, so ranking results are presumably closer to the mind of the decision maker. As a matter of fact, PROMETHEE II suggests that either DS or RT is preferable as the first choice for large farms and expert/policy makers and small farms, respectively. 
In such a case, it would be difficult to explain why most farmers follow CT. From any point of view, the typical practice of farm businesses is not compatible with the suggestions of multicriteria analysis. A plausible explanation would be that one or more assumptions on PROMETHEE parameters and/or weighting are not correct. However, weights are subjective, and they have been estimated by means of questionnaires based on the AHP method collected by three individuals belonging to the designed categories as examples. PROMETHEE parameters (thresholds) are determined based on the performance values corresponding to criteria keeping them the same for all three decision makers. This counterfactual result is due to the very good performance of DS in 3 criteria; at the same time, it means that farmers do not follow the PROMETHEE rationality. As a matter of fact, most often, farmers apply full (conventional) tillage, being their second choice, while few practice RT. For this reason, we implemented the modified PROMETHEE injecting the prospect theory rationale. When we integrate prospect theory elements, namely set "conventional tillage" as the reference alternative and subsequent loss aversion perception as explained in the methodology section in the PROMETHEE preference functions, we observe that the recalculated $\varphi$ values result in different ranking.

Table 5. Calculated $\varphi$ and ranking of alternatives by PROMETHEE II and PT-PROMETHEE.

\begin{tabular}{ccccccc}
\hline Scenario & \multicolumn{2}{c}{$\begin{array}{c}\text { Private Business } \\
\text { (Small Farm) }\end{array}$} & \multicolumn{2}{c}{$\begin{array}{c}\text { Private Business } \\
\text { (Large Farm) }\end{array}$} & \multicolumn{2}{c}{$\begin{array}{c}\text { Policy Maker } \\
\text { (Expert) }\end{array}$} \\
\hline PROMETHEE Version & II & II-PT & II & II-PT & II & II-PT \\
\hline DS & -0.305 & -0.417 & $\mathbf{0 . 8 9 7}$ & $\mathbf{0 . 8 2 6}$ & $\mathbf{0 . 1 6 3}$ & 0.093 \\
RT & $\mathbf{0 . 1 6 1}$ & 0.115 & -0.188 & -0.219 & -0.188 & -0.219 \\
CT & 0.144 & $\mathbf{0 . 3 0 0}$ & -0.709 & -0.608 & 0.025 & $\mathbf{0 . 1 2 5}$ \\
\hline
\end{tabular}

In fact, as shown in Tables 5 and 6, one can observe a rank reversal in two cases (small farm and expert/policy maker), where $\mathrm{CT}$ gets the highest $\varphi$; in other words, it becomes the preferable alternative.

Table 6. Ranking of alternatives by PT-PROMETHEE in the presence of incentives (values of $\varphi$ ).

\begin{tabular}{ccccccc}
\hline Scenario & \multicolumn{2}{c}{$\begin{array}{c}\text { Private Business } \\
\text { (Small Farm) }\end{array}$} & $\begin{array}{c}\text { Private } \\
\text { Business }\end{array}$ & $\begin{array}{c}\text { Subsidy to } \\
\text { Reduce Tillage }\end{array}$ & $\begin{array}{c}\text { Private } \\
\text { Business }\end{array}$ & $\begin{array}{c}\text { Subsidy to } \\
\text { Reduce Tillage }\end{array}$ \\
\hline PROMETHEE Version & Base Case & DS GM & RT GM & DS GM & RT GM \\
$\mathbf{+ 2 8 8 . 2 8}$ & $\mathbf{+ 6 2 . 1 4}$ & $\mathbf{+ 1 9 9 . 3 9}$ & $\mathbf{+ 5 0 . 7 8}$ \\
\hline DS & -0.305 & -0.417 & 0.301 & -0.539 & 0.040 & -0.516 \\
RT & 0.161 & 0.115 & -0.185 & 0.301 & -0.070 & 0.263 \\
CT & 0.144 & 0.300 & -0.116 & 0.238 & 0.030 & 0.253 \\
\hline
\end{tabular}

In the case of the policy maker viewpoint, the modification of preference index calculation alters two partial preference indices. The criterion "mean gross profit" $\Pi(C T, D S)$ increases to 0.336 from 0.167 , so there is a weak preference for CT over DS due to a difference of 120.71 in gross profit; and the criterion "standard deviation of gross profit" $\Pi(C T, R T)$ increases to 1 from 0.273 , so there is a weak preference for CT over RT due to a reduced GP variation of $77.25(-528.92+606.17)$, making it a strict preference. Subsequent changes in entering and leaving flows combined with the preference structure and weights result in overall phi value changes that reverse the rank in favour of the status quo.

In the case of the small farm viewpoint, the fact that environmental criteria are given zero weight, so that they are not considered at all by the small farmer in cultivation practice, the modified preference structure and weight values ranked RT first, with full tillage second. With the PT modification in PROMETHEE affecting the same preference indices as previously, different weights result in higher overall phi values for full tillage, and rank reversal between RT and CT, with the latter amounting to 0.300 (second column in Table 5). 


\subsection{Policy Analysis by Means of PROMETHEE}

Rozakis [53] observes two caveats in multicriteria decision making analysis with regard to environmental problems: firstly, criteria related to environmental dimensions as suggested by scientists are in fact not necessarily adopted by private agents in their decision problems; and secondly, that models used in decision making are most often managerial ones whose optimal solutions do not approximate the observed behaviour of the decision makers in the field. These points are taken into account in this exercise, the first one by arbitrarily selecting two distinct farmer viewpoints in addition to the one of expert/policy maker. Secondly, we emphasize the positive dimension in PROMETHEE by injecting the prospect theory rationale.

There is evidence that the ranking provided by PT-PROMETHEE better reproduces farmers' behaviour; therefore, we can proceed to policy analysis. In the case of small farmer, we can determine the subsidy (increase to gross income per ha) so that the value of $\varphi$ for DS and/or RT to outrank CT. We calculate it by means of simulations using the feature Goalseek in a MS Excel spreadsheet. As a matter of fact, we search how much the gross income of alternative tillage practice (DS or RT) should increase on top of the Basic Payment (currently at 220 euro per ha) so that $\varphi$ (alternative tillage) $=$ $\varphi_{\text {initial }}(C T)+\varepsilon$. Iterative approximation by GoalSeek suggests about 288 and 62 euro per ha for DS and RT, respectively. We observe, however, in Table 6, that after subsidizing, for instance, RT, the value of $\varphi$ becomes much higher compared to the new $\varphi$ value of CT. For this reason, we modified the formula in order to determine the minimum subsidy amount necessary to prefer alternative tillage; in other words, the amount that makes the difference $\varphi$ (alternative tillage $)-\varphi_{\text {initial }}(C T)>\varepsilon$. In this case, required subsidies become about 200 and 51 euro per ha (see in last two columns in Table 6) for DS and $\mathrm{RT}$ respectively, that is a significant decrease from previously estimated minimum additional support.

\subsection{Challenges}

In the face of the variation of agricultural practices that may influence maize sustainability, broader evaluation of maize cultivation practices in different contexts may be useful for determination of the full picture of such systems. For instance, level of fertilization and pesticide use, as well as site-specific factors (soil, climatic conditions), may influence the differences obtained in the same tillage system. Integral soil fertilization aims to fertilization adjust to soil type, planting rate, seed type and moisture regime. Some studies show that maize yield may be increased by hybrid seed use, adapted to local or regional soils and climatic requirements. Conservation agriculture and minimum tillage are defined as improved tillage methods, combining the advantages of conservation of soil moisture, mulching by crop stover and crop rotations [54]. Irrigation is pointed out as a practice that can mitigate drought impacts and ensure the stability of yield. Regrettably, irrigation has not been widely used in Poland due to unfavourable economic and infrastructural conditions [55]. It is important to ensure that there is spatial variation of agricultural environments due to different climate and soil conditions, and also consumer and producer preferences [56].

Due to climate change, instability may be observed in the sustainability of maize cultivation. The main risks in agricultural production related to the crop yield variability are weather conditions [57]. According to many climate models, air temperature, wind speed increase and precipitation sum in summer are predicted to decrease in the northern hemisphere [52]. Climate change, in some European countries, could have a negative impact on crop production due to air temperature that is too high, and frequent droughts [58]. Due to climate change in Poland, more and more harmful and unfavourable weather phenomena have been occurring, which has been driving the climate risk for crop cultivation. This includes droughts, which are becoming increasingly frequent [55]. On the other hand, it has been shown that yield may be increased due to better agronomic management, new seeds, better use of fertilizers and mechanization [59]. 
In addition to agricultural practices, the significant impacts of soil type, microclimate and weather conditions on maize yield have been observed. In Poland, considerable variation in maize yield was observed between regions. In South-Eastern Poland there are more suitable climatic conditions for maize cultivation than in Northern Poland, where heat shortage is still the main limitation on maize production [60]. It has been shown that climate change and projected temperature increase may have a significant influence on crop phenology and agricultural production. Marcinowski et al. established that sowing and harvest date will accelerate in time by 30 days for maize due to the projected warmer climate. Spatial variation between regions has also been shown; in the North-East, the sowing/harvest date is delayed, while in the South-West, it is advanced [61]. Nieróbca et al. analysed weather maize yield index (WI) for Puławy (near to the experimental site) and showed that the climatic conditions for maize cultivation have been improving [60]. Therefore, maize cultivation in Poland has demonstrated associated risks which may be minimised by appropriate decisions in selecting suitable varieties [62].

Decision support systems may be supported by the Geographical Information System (GIS), crop models (e.g., DDSSAT, APSIM) and portals. There is the possibility to indicate suitable areas for maize planting based on a GIS system approach in combination with multicriteria evaluation by using hyper-resolution data of climate (precipitation and temperature) and soil conditions, as well as topography [63]. FACE-IT (Framework to Advance Climate, Economic, and Impact Investigations with IT) may support decisions by providing easy access to data, simulation models, and analysis tools [64].

\section{Conclusions}

In the presence of multidimensional problems, the exploitation of long-term experiments is of high importance. Especially in agriculture, because of the dependence on climate and pedological conditions, well-designed and -monitored pilot cultivations can provide valuable data for this purpose. Such data, along with agronomic knowledge, are elaborated with reference to different tillage practices in Central Poland. Detailed accounts made it possible to measure indicators for a coherent family of criteria, namely financial, social and environmental ones. The outranking methodology was selected as being compatible with incommensurability and non-compensation; specifically, PROMETHEE has been implemented since the eighties in similar and other problems. PROMETHEE was selected for the additional reason of capacity to accommodate advances in behavioural decision making in order to respond to the positive aspect of decision modelling. A recently proposed [9] variant of PROMETHEE was implemented, adding elements of prospect theory to its algorithm enhancing the positive aspect of the model.

The most preferred alternative based on the ranking by the original PROMETHEE II was DS from the expert/policy maker and large farm viewpoint, whereas the RT was preferred by the small farmer. Such a result is puzzling, because the alternative CT, although most often chosen by farmers, is never ranked first. The inclusion of full tillage as the reference point in PT-PROMETHEE reversed the selection ranking for the small farmer and the expert. The status quo effect is related to farmers' reluctance to change, due to the fear of potential losses of new alternatives within any criterion. The result of PT-PROMETHEE illustrates Polish farmers' decisions, thus enabling the analyst to analyse incentives for the farmers to select sustainable overall and also environmental friendly cropping practices.

The findings of this exercise can be generalised in order to come up with coherent policy suggestions concerning tillage practices in maize and other important crops. For this purpose, experimental farm research outcome supported by relevant literature and appropriate data should be projected at the region and/or at the country level. In addition, survey data from groups of representative farmers and other stakeholders need to be collected so that selection and weighting of criteria to be exhaustive and representative so as to enable multiactor multicriteria analysis. 
Author Contributions: A.K. has performed part of the experimental data collection, the data setting and implementation of the multicriteria algorithm, and she was the main contributor to the writing along with S.R. J.K. designed and implemented the field experiment and he supervised the data collection. Also, he advised in the process of paper writing. E.K. contributed to the establishment and implementation of multicriteria methodology and integration of prospect theory to the model. She revised the whole paper as well. S.R. has contributed in the conceptual design and application of the research framework. All authors have read and approved the final manuscript.

Funding: Aleksandra Król acknowledges funding by the Polish National Centre for Research and Development in frame of the project: LCAgri, contract number: BIOSTRATEG 1/271322/3/NCBR/2015. Stelios Rozakis acknowledges financial support from the Widening Program ERA Chair: project BioEcon (H2020), contract number: 669062.

Conflicts of Interest: The authors declare no conflict of interest. The funding sponsors had no role in the design of the study; in the collection, analyses, or interpretation of data; in the writing of the manuscript, and in the decision to publish the results.

\section{References}

1. Central Statistical Office of Poland. Crop Production in 2017. Warsaw, 2018. Available online: https:/ / stat.gov.pl/download/gfx/portalinformacyjny/en/defaultaktualnosci/3332/3/15/1/crop_ production_in_2017.pdf (accessed on 31 July 2018). (In Polish)

2. Sadok, W.; Angevin, F.; Bergez, J.-E.; Bockstaller, C.; Colomb, B.; Guichard, L.; Reau, R.; Doré, T. Ex ante assessment of the sustainability of alternative cropping systems: Implications for using multi-criteria decision-aid methods. A review. Agron. Sustain. Dev. 2008, 28, 163-174. [CrossRef]

3. Kumar, V.; Del Vasto-Terrientes, L.; Valls, A.; Schuhmacher, M. Adaptation strategies for water supply management in a drought prone Mediterranean river basin: Application of outranking method. Sci. Total Environ. 2016, 540, 344-357. [CrossRef] [PubMed]

4. Arondel, C.; Girardin, P. Sorting cropping systems on the basis of their impact on groundwater quality. Eur. J. Oper. Res. 2000, 127, 467-482. [CrossRef]

5. Kylili, A.; Christoforou, E.; Fokaides, P.A.; Polycarpou, P. Multicriteria analysis for the selection of the most appropriate energy crops: The case of Cyprus. Int. J. Sustain. Energy 2016, 35, 47-58. [CrossRef]

6. Azmi, M.; Araghinejad, S.; Sarmadi, F. A national-scale assessment of agricultural development feasibility using multi-criteria decision making (MCDM) approaches. Adv. Nat. Appl. Sci. 2011, 5, 445-457.

7. Nigussie, Y.; van der Werf, E.; Zhu, X.; Simane, B.; van Ierland, E.C. Evaluation of Climate Change Adaptation Alternatives for Smallholder Farmers in the Upper Blue-Nile Basin. Ecol. Econ. 2018, 151, 142-150. [CrossRef]

8. Kahneman, D.; Tversky, A. Prospect Theory-An Analysis of Decision Under Risk. Econometrica 1979, 47, 263-292. [CrossRef]

9. Lerche, N.; Geldermann, J. Integration of prospect theory into PROMETHEE-a case study concerning sustainable bioenergy concepts. Int. J. Multicriteria Decis. Mak. 2015, 5, 309-333. [CrossRef]

10. Księżak, J. Assessment of maize yields as affected by seedbed preparation method. Pol. J. Agron. 2010, 2, 33-40.

11. Czyż, E.A. Effects of cultivation of maize (Zea mays L.) in monoculture and crop rotation on some soil physical properties. Soil Sci. Ann. 2011, 62, 12-24. (In Polish)

12. Garnett, T.; Appleby, M.C.; Balmford, A.; Bateman, I.J.; Benton, T.G.; Bloomer, P.; Burlingame, B.; Dawkins, M.; Dolan, L.; Fraser, D.; et al. Sustainable intensification in agriculture: Premises and policies. Science 2013, 341, 33-34. [CrossRef] [PubMed]

13. Velten, S.; Leventon, J.; Jager, N.; Newig, J. What is sustainable agriculture? A systematic review. Sustainability 2015, 7, 7833-7865. [CrossRef]

14. Craheix, D.; Angevin, F.; Doré, T.; De Tourdonnet, S. Using a multicriteria assessment model to evaluate the sustainability of conservation agriculture at the cropping system level in France. Eur. J. Agron. 2016, 76, 75-86. [CrossRef]

15. Corsi, S.; Friedrich, T.; Kassam, A.; Pisante, M.; de Sà, J.M. Soil Organic Carbon Accumulation and Greenhouse Gas Emission Reductions from Conservation Agriculture: A Literature Review; Food and Agriculture Organization of the United Nations (FAO): Rome, Italy, 2012.

16. Holland, J.M. The environmental consequences of adopting conservation tillage in Europe: Reviewing the evidence. Agric. Ecosyst. Environ. 2004, 103, 1-25. [CrossRef] 
17. Dzienia, S.; Zimny, L.; Weber, R. The newest trends in soil tillage and techniques of sowing. Fragm. Agron. 2006, 2, 227-241. (In Polish)

18. Machul, M. Possibilities and implications of using reduced tillage and direct sowing in maize cultivation. Stud. Rap. IUNG-PIB 2007, 9, 159-170. (In Polish)

19. Smagacz, J. Production, economic and environmental aspects of selected soil tillage practices. Stud. Rap. IUNG-PIB 2012, 29, 121-134. (In Polish)

20. Busari, M.A.; Kukal, S.S.; Kaur, A.; Bhatt, R.; Dulazi, A.A. Conservation tillage impacts on soil, crop and the environment. Int. Soil Water Conserv. Res. 2015, 3, 119-129. [CrossRef]

21. Czyż, E.A.; Dexter, A.R. Effects of different cultivation technologies on soil bulk density and penetration resistance. Soil Sci. Ann. 2010, 61, 40-50. (In Polish)

22. Włodek, S.; Biskupski, A.; Pabin, J.; Kaus, A. Yielding of crops and changes in soil water retention under different systems of tillage. Inzynieria Rolnicza 2007, 11, 195-200. (In Polish)

23. Tambour, L.; Houlès, V.; Cohen-Jonathan, L.; Auffray, V.; Escande, P.; Jallas, E. Design of a model-driven web decision support system in agriculture: Scientific models to the final software. Adv. Model. Agric. Syst. 2009, 25, 67-102. [CrossRef]

24. Księżak, J.; Bojarszczuk, J.; Gałązka, A.; Niedźwiecki, J.; Gawryjołek, K.; Lenc, L.; Jeske, M.; Czyż, E.; Król, M. Research on impacts of seed bed preparation methods of maize cultivation (zea mays L.) in multiyear monoculture and rotation. Monogr. Rozpr. Nauk. IUNG-PIB Puławy 2018, 58, 1-120. (In Polish)

25. Matyka, M.; Kozyra, J.; Kozak, M.; Wawer, R.; Jadczyszyn, T.; Księżak, J.; Jończyk, K.; Smagacz, J.; Pudełko, R.; Borek, R. Plan for the Implementation of Low Carbon Practices to Experimental Station of the Insitiute of Soil Science and Plant Cultivation; State Research Insitute in Grabów: Beavercreek, OH, USA, 2016; unpublished. (In Polish)

26. Ahtiainen, H.; Pouta, E.; Liski, E.; Assmuth, A.; Myyrä, S. Importance of Economic, Social, and Environmental Objectives of Agriculture for Stakeholders-A Meta-Analysis. Agroecol. Sustain. Food Syst. 2015, 39, 1047-1068. [CrossRef]

27. Naresh, R.K.; Singh, S.P.; Dwivedi, A.; Sepat, N.K.; Kumar, V.; Ronaliya, L.K.; Singh, R. Conservation Agriculture Improving Soil Quality for Sustainable Production Systems under Smallholder Farming Conditions in North West India: A Review. Int. J. Life Sci. Bot. Pharm. Res. 2013, 2, 151-213.

28. Blecharczyk, A.; Malecka, I.; Skrzypczak, G. Effect of reduced tillage on yield, weed infestation of maize and soil properties. Acta Sci. Pol. Agric. 2004, 3, 157-163. (In Polish)

29. Sommer, R.; Piggin, C.; Haddad, A.; Hajdibo, A.; Hayek, P.; Khalil, Y. Simulating the effects of zero tillage and crop residue retention on water relations and yield of wheat under rainfed semiarid Mediterranean conditions. Field Crop. Res. 2012, 132, 40-52. [CrossRef]

30. Su, Z.; Zhang, J.; Wu, W.; Cai, D.; Lv, J.; Jiang, G.; Huang, J.; Gao, J.; Hartmann, R.; Gabriels, D. Effects of conservation tillage practices on winter wheat water-use efficiency and crop yield on the Loess Plateau, China. Agric. Water Manag. 2007, 87, 307-314. [CrossRef]

31. Turcksin, L.; Bernardini, A.; Macharis, C. A combined AHP-PROMETHEE approach for selecting the most appropriate policy scenario to stimulate a clean vehicle fleet. Procedia-Soc. Behav. Sci. 2011, 20, 954-965. [CrossRef]

32. Macharis, C.; Springael, J.; De Brucker, K.; Verbeke, A. PROMETHEE and AHP: The design of operational synergies in multicriteria analysis: Strengthening PROMETHEE with ideas of AHP. Eur. J. Oper. Res. 2004, 153, 307-317. [CrossRef]

33. Saaty, T.L. Decision making with the analytic hierarchy process. Int. J. Serv. Sci. 2008, 1, 83-98. [CrossRef]

34. Saaty, T.L. The Analytical Hierarchy Process, Planning, Priority; Resource Allocation RWS Publications: Pittsburgh, PA, USA, 1980.

35. Aguaron, J.; Moreno-Jimenez, J.M. Local stability intervals in the analytic hierarchy process. Eur. J. Oper. Res. 2000, 125, 113-132. [CrossRef]

36. Nardo, M.; Saisana, M.; Saltelli, A.; Tarantola, S.; Hoffman, A.; Giovannin, E. Handbook on Constructing Composite Indicators: Methodology and User Guide; OECD Statistics Working Papers; OECD: Paris, France, 2005.

37. Ziemba, P.; Wątróbski, J. Selected issues of rank reversal problem in anp method. In Selected Issues in Experimental Economics; Nermend, K., Łatuszyńska, M., Eds.; Springer: Berlin, Germany, 2016; pp. $203-225$.

38. Aguaron, J.; Moreno-Jiménez, J.M. The geometric consistency index: Approximated thresholds. Eur. J. Oper. Res. 2003, 147, 137-145. [CrossRef] 
39. Brans, J.P.; Vincke, P.; Mareschal, B. How to select and how to rank projects: The PROMETHEE method. Eur. J. Oper. Res. 1986, 24, 228-238. [CrossRef]

40. Roy, B. Multicriteria Methodology for Decision Aiding; Springer: Boston, MA, USA, 1996; pp. 7-17. ISBN 978-1-4419-4761-1.

41. Geldermann, J.; Spengler, T.; Rentz, O. Fuzzy outranking for environmental assessment. Case study: Iron and steel making industry. Fuzzy Sets Syst. 2000, 115, 45-65. [CrossRef]

42. Goumas, M.; Lygerou, V. An extension of the PROMETHEE method for decision making in fuzzy environment: Ranking of alternative energy exploitation projects. Eur. J. Oper. Res. 2000, 123, 606-613. [CrossRef]

43. Liao, H.; Wu, D.; Huang, Y.; Ren, P.; Xu, Z.; Verma, M. Green Logistic Provider Selection with a Hesitant Fuzzy Linguistic Thermodynamic Method Integrating Cumulative Prospect Theory and PROMETHEE. Sustainability 2018, 10, 1291. [CrossRef]

44. Ziemba, P. NEAT F-PROMETHEE-A New Fuzzy Multiple Criteria Decision Making Method Based on the Adjustment of Mapping Trapezoidal Fuzzy Numbers. Expert Syst. Appl. 2018, 110, 363-380. [CrossRef]

45. Corrente, S.; Greco, S.; Słowiński, R. Multiple criteria hierarchy process with ELECTRE and PROMETHEE. Omega 2013, 41, 820-846. [CrossRef]

46. Ziemba, P.; Watróbski, J.; Zioło, M.; Karczmarczyk, A. Using the PROSA method in offshore wind farm location problems. Energies 2017, 10, 1755. [CrossRef]

47. Ziemba, P.; Jankowski, J.; Watróbski, J. Dynamic Decision Support in the Internet Marketing Management. In Transactions on Computational Collective Intelligence XXIX; Nguyen, N., Kowalczyk, R., Eds.; Springer: Berlin, Germany, 2018; pp. 39-68.

48. Fan, Z.-P.; Zhang, X.; Zhao, Y.-R.; Chen, F.-D. Multiple attribute decision making with multiple formats of attribute aspirations: A method based on prospect theory. Int. J. Inf. Technol. Decis. Mak. 2013, 12, 711-727. [CrossRef]

49. Tversky, A.; Kahneman, D. Advances in prospect theory: Cumulative representation of uncertainty. J. Risk Uncertain. 1992, 5, 297-323. [CrossRef]

50. Gałązka, A.; Gawryjołek, K.; Frąc, J.G.; Księżak, J. Microbial community diversity and the interaction of soil under maize growth in different cultivation techniques. Plant Soil Environ. 2017, 63, 264-270. [CrossRef]

51. Bojarszczuk, J.; Księżak, J.; Gałązka, A. Soil respiration depending on different agricultural practices before maize sowing. Plant Soil Environ. 2017, 63, 435-441. [CrossRef]

52. Graß, R.; Thies, B.; Kersebaum, K.C.; Wachendorf, M. Simulating dry matter yield of two cropping systems with the simulation model HERMES to evaluate impact of future climate change. Eur. J. Agron. 2015, 70, 1-10. [CrossRef]

53. Rozakis, S. Positive multicriteria (PMC) models in agriculture for energy and environmental policy analysis. Int. J. Multicriteria Decis. Mak. 2011, 1, 321. [CrossRef]

54. Donnet, M.L.; López-Becerril, I.D.; Black, J.R.; Hellin, J. Productivity differences and food security: A metafrontier analysis of rain-fed maize farmers in MasAgro in Mexico. AIMS Agric. Food 2017, 2, 129-148. [CrossRef]

55. Żarski, J.; Dudek, S.; Kuśmierek-Tomaszewska, R.; Rolbiecki, R.; Rolbiecki, S. Forecasting effects of plants irrigation based on selected meteorological and agricultural drought indices. Rocz. Ochr. Śr. 2013, 15, 2185-2203. (In Polish)

56. Hartkamp, A.D.; White, J.W.; Aguilar, R.A.; Banziger, M.; Srinivasan, G.; Granados, G.; Crossa, J. Maize Production Environments Revisited: A GIS-Based Approach; CIMMYT \& NRG: Mexico, DF, Mexico, 2000.

57. Górski, T. A probability distribution for crop yields in Poland. Geogr. Pol. 2009, 82, 61-67. [CrossRef]

58. Trnka, M.; Brázdil, R.; Olesen, J.E.; Eitzinger, J.; Zahradníček, P.; Kocmánková, E.; Dobrovolný, P.; Štěpánek, P.; Možný, M.; Bartošová, L.; et al. Could the changes in regional crop yields be a pointer of climatic change? Agric. For. Meteorol. 2012, 166, 62-71. [CrossRef]

59. Xiong, W.; Holman, I.P.; You, L.; Yang, J.; Wu, W. Impacts of observed growing-season warming trends since 1980 on crop yields in China. Reg. Environ. Chang. 2014, 14, 7-16. [CrossRef]

60. Nieróbca, A.; Kozyra, J.; Pudełko, R. Evaluation of meteorological conditions for the cultivation of maize grain in Poland. Acta Agrophys. 2010, 6, 45-55.

61. Marcinkowski, P.; Piniewski, M. Effect of climate change on sowing and harvest dates of spring barley and maize in Poland. Int. Agrophys. 2018, 32, 265-271. [CrossRef] 
62. Zaliwski, A.; Górski, T. Probability of maize ripening-An internet application. Inż. Rol. 2005, 9, 401-408. (In Polish)

63. Jia, C.J.; Luo, X.L.; Zhou, W.H.; Chen, Y.X.; Sun, G.J. Evaluation of suitability areas for maize in china based on GIS and its variation trend on the future climate Condition. In Ecosystem Assessment and Fuzzy Systems Management. Advances in Intelligent Systems and Computing; Cao, B.Y., Ma, S.Q., Cao, H., Eds.; Springer: Berlin, Germany, 2014; pp. 285-299.

64. Montella, R.; Brizius, A.; Elliott, J.; Kelly, D.; Madduri, R.; Maheshwari, K.; Porter, C.; Vilter, P.; Wilde, M.; Xiong, W.; et al. FACE-IT: A science gateway for food security research. Concurr. Comput. Pract. Exp. 2015, 27, 4423-4436. [CrossRef]

(C) 2018 by the authors. Licensee MDPI, Basel, Switzerland. This article is an open access article distributed under the terms and conditions of the Creative Commons Attribution (CC BY) license (http:/ / creativecommons.org/licenses/by/4.0/). 